\title{
Burchard receives the 2019 Georg Wüst Prize
}

\author{
Jörg-Olaf Wolff' ${ }^{1}$ (I)
}

Received: 22 April 2019 / Accepted: 8 May 2019 / Published online: 25 May 2019

C) Springer-Verlag GmbH Germany, part of Springer Nature 2019

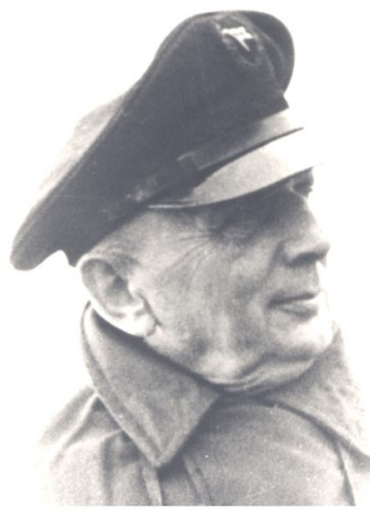

Prof. Dr. Georg Wüst

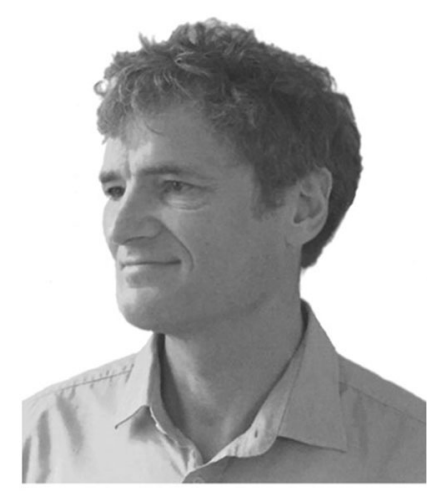

Prof. Dr. Hans Burchard
Prof. Dr. Hans Burchard received the Georg Wüst Prize 2019 at the European Geophysical Union (EGU) General Assembly in Vienna, Austria, April 2019. This biannual prize is awarded for outstanding contributions to the general field of oceanography and is sponsored by the German Society for Marine Research and Ocean Dynamics. The following is a transcript of the citation by Mr. Schweikert and Prof. Wolff and the response by Prof. Burchard.

\section{Citation by Mr. Schweikert:}

It is our great honor and distinct pleasure to announce Prof. Hans Burchard (Leibniz Institute for Baltic Research Warnemünde, Germany) as this years recipient of the Georg Wüst Prize. And thank you very much for your great presentation related to the data set from Georg Wüst's expedition through the Baltic, which reminds and highlights

Responsible Editor: Emil Vassilev Stanev

Jörg-Olaf Wolff

wolff@icbm.de

1 Institute for Chemistry and Biology of the Marine

Environment (ICBM), Department of Physical Oceanography

(Theory), Carl von Ossietzky Universität Oldenburg,

Carl-von-Ossietzky-Str. 9-11, Oldenburg, 26111, Germany the work of Georg Wüst perfectly. The biannual award is presented for the eighth time by the German Society for Marine Research (DGM, Deutsche Gesellschaft für Meeresforschung) and kindly supported by the publisher Springer and the Journal Ocean Dynamics.

The German Society for Marine Research with about 400 members wants to support communication and networking between scientists in ocean research. For example, we celebrate this year the 10th edition of the successful YOUMARES (YOUng MArine RESearchers) conference series for young marine researchers in Hamburg and we started to organize an annual national meeting for the German Marine Researchers Community, the "Ocean Forum" also held in Hamburg 1 day before the YOUMARES conference with the possibility to network between experienced and young researchers. Wherever possible, we seek to highlight and honor outstanding scientific contributions in ocean research. The Georg Wüst Prize honors excellent mid-career scientists. By that, the prize fills a gap between numerous awards for early career scientists and lifetime achievements.

The inaugural presentation of the Georg Wüst Prize was in 2005 in Vienna at the EGU general assembly. Arnold Gordon and Jörg-Olaf Wolff presented the award to Stephen Rintoul. In the following years, an illustrious group of marine researchers was awarded: Eberhard Fahrbach (2007), Karen Heywood (2009), Andreas Oschlies (2011), Gregory Johnson (2013), Carsten Eden (2015), Ilker Fer (2017), and now Hans Burchard.

Congratulations Hans!

\section{Frank Schweikert}

Vice-President German Society for Marine Research

\section{Citation by Prof. Wolff:}

As Chief Editor of Ocean Dynamics, it is my honor and distinct pleasure to present the Georg Wüst Prize 2019 to Prof. Hans Burchard. Before presenting the achievements 
of Hans Burchard, I first quote from Arnold Gordon's statement at the 2005 ceremony concerning Georg Wüst's achievements.

Georg Wüst, born 15 June 1890, brought descriptive oceanography into the modern era. Through a careful analysis of each hard-won observational data point that passed his meticulous quality control procedures, he probed into the secrets of the ocean, contributing to several research areas. He is best known for his Atlantic Ocean studies (Wüst 1935), where with great insight and skill, he combined water mass analysis by means of the temperature-salinity relationship and the core method, with the dynamic approach of geostrophic balance, to reveal the nature of the deep Atlantic's stratification and circulation.

Coming now to Hans Burchard, I quote from the nomination letter:

Hans' first contributions, resulting from his $\mathrm{PhD}$ thesis, were related to turbulence parameterization. This is a complicated field, with many authors putting forth numerical schemes to use numerically resolved fields (at a 1-10-m vertical scale) of velocity and density and use them to predict turbulence intensity at a millimeter scale. Through his PhD work and many subsequent papers, Hans brought order to the field showing that many of the most used schemes could be expressed in a single framework with variation of a few key numerical factors. This generic length scale framework was made immediately accessible to other scientists through the General Ocean Turbulence Model (GOTM) of which Hans is a major developer. The framework is now incorporated into the Regional Ocean Modeling System (ROMS), a model used by scientists worldwide, especially for regional coastal and estuarine applications.

Through this work, Hans made it possible for other scientists to rapidly evaluate the effect of different turbulence parameterizations on model performance, ushering in a new era in which estuarine and coastal models have attained extraordinary skill. Hans was also a major developer of the General Estuarine Transport Model (GETM), which is widely used in estuaries and marginal seas for state-of-the-art studies of circulation, sediment transport, and biogeochemical interactions.

Two examples of Hans contributions to numerical methods stand out for their wider impact and creativity. He pioneered a method for using loss of tracer variance to quantify numerical mixing in circulation models. The result, which is still not fully appreciated by the modeling community (but will be) is that often as much as half of the mixing that occurs in realistic coastal and estuarine models is due to numerics, and has little to do with the carefully constructed turbulence parameterization. The use of variance also prompted other discoveries in estuarine physics, described below. The other key numerical invention has been to pursue vertically adaptive coordinates to better model strong pycnoclines typical of some shelf seas like the Baltic.

In the field of estuarine physics, Hans has made many contributions, the most important of which is detailed in a series of recent papers where he developed a clever method for clearly decomposing the tidally averaged momentum balance in a model estuary into different physical mechanisms. The result was that the circulation driven by the covariance of shear and eddy viscosity was found to be more important than the classical gravitational circulation in tidally energetic systems. While this had been an idea floating around in the community for some years, Hans, working with Rob Hetland, was the first to develop a clear method for quantifying it, and to rigorously test it across a wide range of parameter space.

More recently, Hans has been at the forefront of two additional important developments in estuarine physics. The first involves the so-called total exchange flow, a method for analyzing the estuarine exchange flow in salinity coordinates. This produces integral properties of transport and transport-weighted salinity that exactly satisfy the Knudsen (1900) relations. Hans was lead author of a 2018 Progress in Oceanography paper (Burchard et al. 2018) that applied this method to the Baltic (the original site of Knudsens analysis). The paper included a translation of Knudsen (1900) into English as an appendix. I see this as an important and selfless contribution to our community-we have been citing this paper for decades but most of us had never read it!

The other major discovery comes originally from Hans use of salinity variance in the quantification of numerical mixing. Hans, working closely with Rocky Geyer, finally came up with the stunning result that net estuarine mixing, when defined in terms of destruction of salinity variance, could be related to the estuarine exchange flow in a surprisingly simple relationship.

Throughout his work, Hans has proved to be able to make fundamental contributions to the details of numerical methods, the physics of turbulence, and resulting system-wide dynamics and simulation.

In summary, Hans is a great asset in our community. $\mathrm{He}$ is extraordinarily productive, collaborates widely, and has created or expanded the most important tools 
and ideas used in estuarine and coastal dynamics at this time.

The following remark from Arnold Gordon in the citation 14 years ago clearly demonstrates Wüst's vision of progress in ocean sciences:

Wüst (1964) stated that oceanographic progress depends directly on the observations from the great ocean expeditions, with advances hinged on technology, improvement of instrumentation, and data analysis closely linked to the development of new theoretical concepts.

The prize consists of a 3-D laser-engraved picture of the old RV METEOR in a glass block, a prize certificate, an honorary lifetime membership of the German Society of Marine Research, and a prize money of $€ 1500$.

\section{Congratulations Hans!}

\section{Prof. Dr. Jörg-Olaf Wolff}

Chief Editor, Ocean Dynamics

\section{Response by Prof. Burchard:}

Since I was informed that I receive the Georg Wüst Prize, I feel deeply honored and I am happy that my scientific contributions have been appreciated so much by the scientific community. I am grateful to Frank Schweikert and Jörg-Olaf Wolff as well as to the German Society for Marine Research and Ocean Dynamics for awarding me with this prize. I received my $\mathrm{PhD}$ relatively late, 24 years ago at the age of 36 . Being honored as a mid-career scientist, therefore, motivates me to go on doing science my way for quite a while. As a scientist, I should ask the questions "Why do I receive it?" and "How did it come to that?" To find the answers, I need to go back to my PhD times when I was in the middle of the transition from an Applied Mathematician to a Physical Oceanographer and briefly move through my career starting from there.

Becoming a professor or receiving an award was beyond my imagination when I was a PhD student. But without realizing, I was on track already. The task for my $\mathrm{PhD}$, given to me by my supervisor Helmut Baumert, was to extend an existing ocean model equipped with a $k-\epsilon$ turbulence closure towards applications with drying and flooding of mudflats. A seemingly very technical task (today, I would be crucified as a supervisor for giving such a task to a PhD student), but I was happy to be allowed to do it my way. Indeed, I never touched that ocean model. Instead, I started writing a new ocean model with $k-\epsilon$ turbulence closure and drying and flooding from scratch. To do so, I started recoding the $k-\epsilon$ model from literature as a one-dimensional model. Helmut Baumert asked me to use North Sea data of a storm impact on the surface mixedlayer depth as test case for the $k-\epsilon$ model. But, it did not work. Then, I dug deeper into the problem, filling 100 s of pages of paper with calculations, and found that a well-accepted parameter should have a completely different value. I could also explain physically why it should be like that. The boundary conditions did not work either the way they had been published. After filling another 100s of pages with notes, I fixed that problem. Finally, I transferred these solutions to other turbulence closure models, and they worked much better, without any dirty tricks.

What is a solution to a problem without giving people a tool to use it? The tool I had made was called mixedlayermodel.f, a monolithic FORTRAN code which needed to be rewritten for each new application, i.e., quite an unhandy code. It was Karsten Bolding who made this tool available for the community. He rewrote the code and converted it to a modern model in a modular way. He invented the name GOTM (General Ocean Turbulence Model) and created the website gotm.net, such that the two of us could offer the code to the entire scientific community 20 years ago. Later, Lars Umlauf joined the GOTM development and created the generic length scale as a generalization, such that "Hans brought order to the field" mentioned in the nomination letter should be amended by "and Lars put it into a generalized context."

During my $\mathrm{PhD}$, I had actually succeeded to write an ocean model with a $k-\epsilon$ turbulence closure and drying and flooding, but today I do not even remember its name. It worked, but was written in geopotential coordinates, which as I painfully learned does not work for the coastal ocean. As Postdoc, I dumped the model, and wrote a new one, this time based on bottom-following coordinates (including a $k-\epsilon$ turbulence closure and drying and flooding) and called it mudflat.f. Without Karsten Bolding, it would have died the same way as my nameless $\mathrm{PhD}$ ocean model. Same story as for GOTM: He rewrote the code and converted it to a modern model tool in a modular way. This time, I invented the name GETM (General Estuarine Transport Model) and he created the website getm.eu, such that the two of us could offer the code to the entire scientific community. That was 17 years ago. Both models, GOTM and GETM, still exist and do their job.

Without the miracle coding skills of Karsten Bolding, no one would know about these models and the physics and numerics behind them. And I would not have been awarded with the Georg Wüst Prize.

As stated in the nomination letter, there are other research results that motivate the award. But the pattern is always the same: A task comes up and I do not understand how 
it works. I try to make it work for the right reason. At the end, I have learned something, which I try to communicate to the scientific community. Here are some examples: the generation of estuarine turbidity maxima (task by Helmut Baumert who thought of a kind of snow-plow-like process, but it was mainly tidal straining in that case). The role of tidal straining for generating estuarine circulation (Rocky Geyer did not believe in it, and I, with Rob Hetland, showed by means of rigorous model analysis that it is important). Total Exchange Flow: I only started to understand it, after I coded it and convinced myself that the estuarine exchange flow must be related to estuarine mixing. Parker MacCready and Rocky Geyer had the same thought at the same time, and we came up with different but consistent solutions.

There are several other examples, and my approach is always to first try to solve the problem myself and then look into the literature. Probably nothing to be recommended to young scientists, but a way that suits my way of thinking.

The achievements listed in the nomination letter were only possible by close and long-lasting collaborations with bright and skilled colleagues. I feel indepted to Jürgen Sündermann (for supporting my early career over one decade and several stages: Hamburg-Hørsholm-IspraHamburg-Warnemünde), to Helmut Baumert (for giving me challenging tasks and the support to solve them), to Karsten Bolding (for making great models useful to the community), to Julie Pietrzak (for her warning "Beware of the numerics!"), to Jean-Marie Beckers (for solving numerical problems proposed by me), to Eric Deleersnijder (for proposing numerical problems to be solved by me), to John Simpson (for SIPS and ROFI and the Simpson number), to Lars Umlauf (for making the physics behind things visible), to Rob Hetland (for seeing the potential of mathematical solutions), to Chari Pattiaratchi (for making the PECS community being my scientific home base), to Rocky Geyer (for not believing mathematical solutions until he has to), to Parker MacCready (for preferring estuarine physics over estuarine mathematics), to Henk Schuttelaars (for insisting to understand what I say), to Ulf Gräwe (for making the best model setups I have ever seen), to Knut Klingbeil (for correcting all my physical flaws without making fun of me), and to all those PhD students, Postdocs, and national and international colleagues who must remain unmentioned due to the page limit for this text. And ultimately, I am grateful for my family always asking me what the hack I am doing all day and who very much envies me for exactly doing that.

Prof. Dr. Hans Burchard

Leibniz Institute for Baltic Research, Warnemünde, Germany

\section{References}

Burchard H, Bolding K, Feistel R, Gräwe U, MacCready P, Klingbeil K, Mohrholz V, Umlauf L, van der Lee EM (2018) The Knudsen theorem and the total exchange flow analysis framework applied to the Baltic Sea. Progr Oceanogr 165:268-286

Knudsen M (1900) Ein hydrographischer Lehrsatz. Hydrogr Mar Meteorol 28(7):316-320. in German

Wüst G (1935) Schichtung und Zirkulation des atlantischen Ozeans: die Stratosphäre. In: Wissenschaftliche Ergebnisse der deutschen atlantischen Expedition auf dem Forschungs- und Vermessungsschiff "Meteor", vol 6, pp 1925-1927. first part, 2, Berlin, 180 pp. (English translation: Emery WJ, ed.1978. The Stratosphere of the Atlantic Ocean. Amerind, New Delhi, 112 pp.)

Wüst G (1964) The major deep-sea expeditions and research vessels 1873-1960, a contribution to the history of oceanography. Prog Oceanogr 2:1-52. https://doi.org/10.1016/0079-6611(64)90002-3 